\title{
Pentafluoropropionic Acid: An Efficient and Metal-Free Catalyst for the One-Pot Synthesis of Tetrahydrobenzo $[b]$ pyran Derivatives
}

\author{
Naser Montazeri, ${ }^{1}$ Taghva Noghani, ${ }^{1}$ Mona Ghorchibeigy, ${ }^{2}$ and Rozita Zoghi ${ }^{1}$ \\ ${ }^{1}$ Department of Chemistry, Faculty of Sciences, Islamic Azad University, Tonekabon Branch, Tonekabon 46819-89711, Iran \\ ${ }^{2}$ Young Researchers Club, Islamic Azad University, Tonekabon Branch, Tonekabon 46819-89711, Iran \\ Correspondence should be addressed to Naser Montazeri; montazer1350@gmail.com
}

Received 19 January 2014; Accepted 28 March 2014; Published 23 April 2014

Academic Editor: Mohamed Afzal Pasha

Copyright (C) 2014 Naser Montazeri et al. This is an open access article distributed under the Creative Commons Attribution License, which permits unrestricted use, distribution, and reproduction in any medium, provided the original work is properly cited.

Pentafluoropropionic acid (PFPA) efficiently catalyzes the one-pot, three-component reaction of aromatic aldehyde, malononitrile, and dimedone to yield tetrahydrobenzo[b]pyran derivatives in high yields. This method is of great value because of its easy processing, short reaction time, environmentally, and high yields.

\section{Introduction}

Tetrahydrobenzo $[b]$ pyran derivatives are important classes of heterocyclic compounds. Tetrahydrobenzo[b]pyran compounds are known to possess a variety of biological activities, such as anticoagulant, spasmolytic, diuretic, anticancer, and antianaphylactin properties [1-5]. Furthermore these compounds can be employed as pigments, and they constitute the structural unit of a series of natural products $[6,7]$. In view of different biological and chemical applications of tetrahydrobenzo[ $b]$ pyran derivatives, the development of suitable synthetic methodologies for generation has been a topic of great interest in recent times [8]. A number of 2amino-tetrahydropyran derivatives are useful as photoactive materials [9]. Several methods have been reported for the synthesis of tetrahydrobenzo $[b]$ pyran derivatives from aromatic aldehydes, dimedone, and malononitrile, involving the use of catalysts such as $\mathrm{ZnO}$-beta zeolite [10], Mw-NaBr [11], $\mathrm{Na}_{2} \mathrm{SeO}_{4}$ [12], Caro's acide- $\mathrm{SiO}_{2}$ [13], trisodium citrate [14], $\mathrm{PPA}^{-\mathrm{SiO}_{2}}$ [15], KF-basic alumina under ultrasound irradiation [16], TEBA [17], 1-butyl-3-methylimidazolium hydroxide [18], sodium hypochlorite [19], 1,4-diazabicyclo[2.2.2] octane (DABCO) [20], triethylamine [21], $\mathrm{Ce}_{1} \mathrm{Mg}_{x} \mathrm{Zr}_{1-x} \mathrm{O}_{2}$ [22], silica gel supported polyamine [23], urea-choline chloride [24], 2,2,2-trifluoroethanol [25], tetramethyl ammonium hydroxide [26], ammonium acetate [27], and tetrabutylammonium bromide [28].

However, most of these procedures have significant drawbacks such as harsh reaction conditions, difficult workup, and expensive reagents. These problems promoted us towards further investigation in search for a new catalyst, which will carry out the synthesis of tetrahydrobenzo[b]pyrans under simpler experimental setup. In continuation of our efforts to develop novel synthetic routes using metal-free catalysts in organic reactions [29-31], and due to our interest in the synthesis of heterocyclic compounds [32], herein we wish to report an efficient synthesis of tetrahydrobenzo[ $[b]$ pyran derivatives by cyclocondensation reaction of aromatic aldehydes, dimedone, and malononitrile using pentafluoropropionic acid as a metal-free catalyst (Scheme 1).

\section{Experimental}

2.1. General. All chemicals were obtained from Merck or Fluka and were used without further purification. Melting points were recorded on an electrothermal type 9100 melting point apparatus and are uncorrected. Infrared spectra were obtained in $\mathrm{KBr}$ disks on shimadzu IR-470 spectrometer. ${ }^{1} \mathrm{H}$ NMR and ${ }^{13} \mathrm{C}$ NMR spectra were recorded on a Bruker, 
TABLE 1: Optimizing the reaction conditions ${ }^{\mathrm{a}}$.

\begin{tabular}{|c|c|c|c|c|c|}
\hline Entry & Catalyst (mol\%) & Solvent & Condition & Time $(\min )$ & Yield $(\%)^{b}$ \\
\hline 1 & - & $\mathrm{EtOH}$ & Reflux & 150 & 30 \\
\hline 2 & - & $\mathrm{H}_{2} \mathrm{O}$ & Reflux & 150 & 32 \\
\hline 3 & - & $\mathrm{CHCl}_{3}$ & Reflux & 180 & 25 \\
\hline 4 & - & $\mathrm{CH}_{3} \mathrm{CN}$ & Reflux & 150 & 28 \\
\hline 5 & - & $\mathrm{EtOH}: \mathrm{H}_{2} \mathrm{O}(1: 1)$ & Reflux & 120 & 34 \\
\hline 6 & - & $\mathrm{EtOH}$ & r.t & 180 & Trace \\
\hline 7 & - & $\mathrm{H}_{2} \mathrm{O}$ & r.t & 180 & Trace \\
\hline 8 & - & $\mathrm{CHCl}_{3}$ & r.t & 180 & Trace \\
\hline 9 & - & $\mathrm{CH}_{3} \mathrm{CN}$ & r.t & 180 & Trace \\
\hline 10 & - & $\mathrm{EtOH}: \mathrm{H}_{2} \mathrm{O}(1: 1)$ & r.t & 180 & Trace \\
\hline 11 & (PFPA) 30 & - & r.t & 100 & 55 \\
\hline 12 & (PFPA) 35 & - & r.t & 100 & 66 \\
\hline 13 & (PFPA) 40 & - & r.t & 100 & 64 \\
\hline 14 & (PFPA) 30 & $\mathrm{EtOH}: \mathrm{H}_{2} \mathrm{O}(1: 1)$ & r.t & 120 & 85 \\
\hline 15 & (PFPA) 35 & $\mathrm{EtOH}: \mathrm{H}_{2} \mathrm{O}(1: 1)$ & r.t & 80 & 90 \\
\hline 16 & (PFPA) 40 & $\mathrm{EtOH}: \mathrm{H}_{2} \mathrm{O}(1: 1)$ & r.t & 80 & 90 \\
\hline 17 & (PFPA) 35 & $\mathrm{EtOH}$ & r.t & 100 & 65 \\
\hline 18 & (PFPA) 35 & $\mathrm{H}_{2} \mathrm{O}$ & r.t & 100 & 68 \\
\hline 19 & (PFPA) 35 & $\mathrm{CHCl}_{3}$ & r.t & 120 & 47 \\
\hline 20 & (PFPA) 35 & $\mathrm{CH}_{3} \mathrm{CN}$ & r.t & 100 & 56 \\
\hline 21 & (TFAA) 30 & - & r.t & 150 & 41 \\
\hline 22 & (TFAA) 35 & - & r.t & 150 & 52 \\
\hline 23 & (TFAA) 40 & - & r.t & 150 & 51 \\
\hline 24 & (TFAA) 30 & $\mathrm{EtOH}: \mathrm{H}_{2} \mathrm{O}(1: 1)$ & r.t & 150 & 73 \\
\hline 25 & (TFAA) 35 & $\mathrm{EtOH}: \mathrm{H}_{2} \mathrm{O}(1: 1)$ & r.t & 120 & 77 \\
\hline 26 & (TFAA) 40 & $\mathrm{EtOH}: \mathrm{H}_{2} \mathrm{O}(1: 1)$ & r.t & 120 & 79 \\
\hline 27 & (TFAA) 35 & $\mathrm{EtOH}$ & r.t & 120 & 36 \\
\hline 28 & (TFAA) 35 & $\mathrm{H}_{2} \mathrm{O}$ & r.t & 120 & 33 \\
\hline 29 & (TFAA) 35 & $\mathrm{CHCl}_{3}$ & r.t & 180 & 24 \\
\hline 30 & (TFAA) 35 & $\mathrm{CH}_{3} \mathrm{CN}$ & r.t & 120 & 29 \\
\hline
\end{tabular}

${ }^{a}$ Benzaldehyde $(1 \mathrm{mmol})$, dimedone $(1 \mathrm{mmol})$, and malononitrile $(1.2 \mathrm{mmol})$.

${ }^{\mathrm{b}}$ Isolated yields.

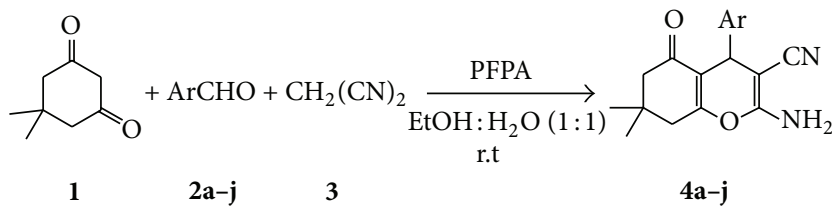

Scheme 1: Synthesis of tetrahydrobenzo[b]pyrans catalyzed by pentafluoropropionic acid.

DRX-400 Avance Bruker spectrometer, at $400.13 \mathrm{MHz}$ and 100.22 $\mathrm{MHz}$, respectively, in $\mathrm{CDCl}_{3}$ and chemical shifts are in ppm $(\delta)$ relative to internal TMS.

2.2. General Procedure for the Synthesis of Tetrahydrobe$n z o[b]$ pyrans $(\mathbf{4 a}-\mathbf{j})$. A solution of dimedone 1 (1 mmol), an aromatic aldehyde $\mathbf{2 a}-\mathbf{j}(1 \mathrm{mmol})$, malononitrile $3(1.2 \mathrm{mmol})$, and pentafluoropropionic acid $(35 \mathrm{~mol} \%)$ in $\mathrm{H}_{2} \mathrm{O}(10 \mathrm{~mL})$ and $\mathrm{EtOH}(10 \mathrm{~mL})$ was stirred at room temperature for the time period as indicated in Table 1 . The progress of the reaction was monitored by TLC. After completion of reaction, the solid product was collected by filtration and recrystallized from ethanol to afford pure products $\mathbf{4 a - j}$ (Table 2) in high yields. All the products were identified by comparison of spectral data (IR and ${ }^{1} \mathrm{H}$ NMR) and m.p. with those reported.

\subsection{Physical and Spectral Data for the Selected Compounds}

2-Amino-3-cyano-5, 6,7,8-tetrahydro-7,7-dimethyl-5-oxo-4phenyl-4H-benzopyran (4a). m.p. $=227-229^{\circ} \mathrm{C}$; IR $(\mathrm{KBr})$ $\mathrm{cm}^{-1}$ 3410, $3330\left(\mathrm{NH}_{2}\right), 3050(\mathrm{C}-\mathrm{H}), 2233(\mathrm{CN}), 1681(\mathrm{C}=\mathrm{O})$, 1380 (C-O); ${ }^{1} \mathrm{H}$ NMR (400.13 MHz, $\left.\mathrm{CDCl}_{3}\right) \delta$ (ppm): $7.32-7.19(\mathrm{~m}, 5 \mathrm{H}), 4.56\left(\mathrm{~s}, 2 \mathrm{H}, \mathrm{NH}_{2}\right), 4.42$ (s, 1H, CH), 2.47 $\left(\mathrm{dd}, 2 \mathrm{H}, J=19.2 \mathrm{~Hz}, \mathrm{CH}_{2}\right), 2.24\left(\mathrm{dd}, 2 \mathrm{H}, J=16 \mathrm{~Hz}, \mathrm{CH}_{2}\right)$, $1.13\left(\mathrm{~s}, 3 \mathrm{H}, \mathrm{CH}_{3}\right), 1.06$ (s, 3H, $\mathrm{CH}_{3}$ ).

2-Amino-3-cyano-5,6,7,8-tetrahydro-7,7-dimethyl-4-(3-nitrophenyl)-5-oxo-4H-benzopyran (4b). m.p. $=207-210^{\circ} \mathrm{C}$; IR 
TABLE 2: Synthesis of tetrahydrobenzo[b]pyrans using pentafluoropropionic acid as catalyst ${ }^{\mathrm{a}}$.

\begin{tabular}{lccccc}
\hline Entry & $\mathrm{Ar}$ & Product $^{\mathrm{b}}$ & Time $(\mathrm{min})$ & ${\text { Yield }(\%)^{\mathrm{c}}}^{\mathrm{m} . \mathrm{p} .\left(^{\circ} \mathrm{C}\right)[\mathrm{reference}]}$ \\
\hline 1 & $\mathrm{C}_{6} \mathrm{H}_{5}$ & $4 \mathrm{a}$ & 80 & 90 & $227-229[28]$ \\
2 & $3-\mathrm{NO}_{2} \mathrm{C}_{6} \mathrm{H}_{4}$ & $4 \mathrm{~b}$ & 80 & 89 & $207-210[28]$ \\
3 & $4-\mathrm{MeOC}_{6} \mathrm{H}_{4}$ & $4 \mathrm{c}$ & 60 & 90 & $197-199[22]$ \\
4 & $4-\mathrm{MeC}_{6} \mathrm{H}_{4}$ & $4 \mathrm{~d}$ & 60 & 90 & $216-218[13]$ \\
5 & $4-\mathrm{BrC}_{6} \mathrm{H}_{4}$ & $4 \mathrm{e}$ & 60 & 90 & $206-208[10]$ \\
6 & $3-\mathrm{MeOC}_{6} \mathrm{H}_{4}$ & $4 \mathrm{f}$ & 80 & 89 & $207-209[-]$ \\
7 & $3-\mathrm{ClC}_{6} \mathrm{H}_{4}$ & $4 \mathrm{~g}$ & 80 & 92 & $223-224[13]$ \\
8 & $4-\mathrm{ClC}_{6} \mathrm{H}_{4}$ & $4 \mathrm{~h}$ & 60 & 89 & $213-215[11]$ \\
9 & $2-\mathrm{ClC}_{6} \mathrm{H}_{4}$ & $4 \mathrm{i}$ & 80 & 90 & $203-205[14]$ \\
10 & $4-\mathrm{HOC}_{6} \mathrm{H}_{4}$ & $4 \mathrm{j}$ & 80 & $206-208[22]$ \\
\hline
\end{tabular}

${ }^{\mathrm{a}}$ Aromatic aldehyde $(1 \mathrm{mmol})$, dimedone $(1 \mathrm{mmol})$, malononitrile $(1.2 \mathrm{mmol})$, and PFPA (35 mol\%) in the mixture of EtOH : $\mathrm{H}_{2} \mathrm{O}(1: 1)$.

${ }^{b}$ The products were characterized by comparison of their spectroscopic and physical data with those reported in the literature.

${ }^{\mathrm{c}}$ Isolated yield.

TABLE 3: Comparison of efficiency of various catalysts in synthesis of tetrahydrobenzo[b]pyrans.

\begin{tabular}{|c|c|c|c|c|c|}
\hline Entry & Catalyst & Conditions & Time $(\min )$ & Yield (\%) & Reference \\
\hline 1 & Trisodium citrate & $\mathrm{EtOH}-\mathrm{H}_{2} \mathrm{O}$; reflux & $5-120$ & $80-96$ & {$[14]$} \\
\hline 2 & $\mathrm{Na}_{2} \mathrm{SeSO}_{4}$ & $\mathrm{EtOH}-\mathrm{H}_{2} \mathrm{O}$; reflux & $30-180$ & $85-98$ & {$[12]$} \\
\hline 3 & PPA- $\mathrm{SiO}_{2}$ & $\mathrm{H}_{2} \mathrm{O}$; reflux & $8-15$ & $77-93$ & {$[15]$} \\
\hline 4 & Caro's acid- $\mathrm{SiO}_{2}$ & $\mathrm{EtOH}-\mathrm{H}_{2} \mathrm{O}$; reflux & $15-20$ & $92-95$ & [13] \\
\hline 5 & $\mathrm{ZnO}$-beta zeolite & EtOH; reflux & $35-52$ & $86-95$ & {$[10]$} \\
\hline 6 & $\mathrm{NaBr}$ & $\mathrm{MW} ; 70-80^{\circ} \mathrm{C}$ & $10-15$ & $85-95$ & [11] \\
\hline 7 & TBAB & EtOH; reflux & $20-140$ & $87-95$ & {$[28]$} \\
\hline 8 & $\mathrm{NaOCl}$ & Grinding & $10-30$ & $80-88$ & {$[19]$} \\
\hline 9 & $\mathrm{Ce}_{1} \mathrm{Mg}_{x} \mathrm{Zr}_{1-x} \mathrm{O}_{2}$ & EtOH; reflux & $35-45$ & $90-94$ & {$[22]$} \\
\hline 10 & Supported polyamine & EtOH- $\mathrm{H}_{2} \mathrm{O}$; reflux & $120-220$ & $88-95$ & {$[23]$} \\
\hline 11 & Urea-ChCl & $80^{\circ} \mathrm{C}$ & $60-240$ & $75-95$ & {$[24]$} \\
\hline 12 & ТМAH & $\mathrm{H}_{2} \mathrm{O}$; r.t. & $30-120$ & $80-92$ & {$[26]$} \\
\hline 13 & PFPA & EtOH- $\mathrm{H}_{2} \mathrm{O}$; r.t. & $60-80$ & $89-92$ & This work \\
\hline
\end{tabular}

$(\mathrm{KBr}) \mathrm{cm}^{-1} 3420,3300\left(\mathrm{NH}_{2}\right), 3012(\mathrm{C}-\mathrm{H}), 2257(\mathrm{CN}), 1710$ $(\mathrm{C}=\mathrm{O}), 1557,1360\left(\mathrm{NO}_{2}\right) ;{ }^{1} \mathrm{H}$ NMR $\left(400.13 \mathrm{MHz}, \mathrm{CDCl}_{3}\right) \delta$ (ppm): 8.11-7.48 (m, $4 \mathrm{H}), 4.80\left(\mathrm{~s}, 2 \mathrm{H}, \mathrm{NH}_{2}\right), 4.53(\mathrm{~s}, 1 \mathrm{H}, \mathrm{CH})$, $2.50\left(\mathrm{dd}, J=13.2 \mathrm{~Hz}, 2 \mathrm{H}, \mathrm{CH}_{2}\right), 2.25(\mathrm{dd}, J=16 \mathrm{~Hz}, 2 \mathrm{H}$, $\left.\mathrm{CH}_{2}\right), 1.12\left(\mathrm{~s}, 3 \mathrm{H}, \mathrm{CH}_{3}\right), 1.08\left(\mathrm{~s}, 3 \mathrm{H}, \mathrm{CH}_{3}\right)$.

2-Amino-3-cyano-5,6,7,8-tetrahydro-7,7-dimethyl-4-(4methylphenyl)-5-oxo-4H-benzopyran (4d). m.p. $=216-218^{\circ} \mathrm{C}$; IR $(\mathrm{KBr}) \mathrm{cm}^{-1}$ 3421, $3297\left(\mathrm{NH}_{2}\right), 2966(\mathrm{C}-\mathrm{H}), 2194(\mathrm{CN})$, $1674(\mathrm{C}=\mathrm{O}), 1369(\mathrm{C}-\mathrm{O}) ;{ }^{1} \mathrm{H}$ NMR $\left(400.13 \mathrm{MHz}, \mathrm{CDCl}_{3}\right) \delta$ (ppm): 7.08-7.14 (m, 4H), $4.54\left(\mathrm{~s}, 2 \mathrm{H}, \mathrm{NH}_{2}\right), 4.38$ (s, $\left.1 \mathrm{H}, \mathrm{CH}\right)$, $2.46\left(\mathrm{dd}, J=5.2 \mathrm{~Hz}, 2 \mathrm{H}, \mathrm{CH}_{2}\right), 2.29\left(\mathrm{~s}, 3 \mathrm{H}, \mathrm{CH}_{3}\right), 2.23(\mathrm{dd}$, $\left.J=5.6 \mathrm{~Hz}, 2 \mathrm{H}, \mathrm{CH}_{2}\right), 1.12\left(\mathrm{~s}, 3 \mathrm{H}, \mathrm{CH}_{3}\right), 1.06\left(\mathrm{~s}, 3 \mathrm{H}, \mathrm{CH}_{3}\right)$.

2-Amino-3-cyano-5,6,7,8-tetrahydro-7,7-dimethyl-4-(3methoxyphenyl-5-oxo-4H-benzopyran (4f). m.p. $=207-$ $209^{\circ} \mathrm{C}$; IR (KBr) cm ${ }^{-1}$ 3397, $3291\left(\mathrm{NH}_{2}\right), 2295(\mathrm{CN}), 1678$ $(\mathrm{C}=\mathrm{O}), 1384(\mathrm{C}-\mathrm{O}) ;{ }^{1} \mathrm{H}$ NMR $\left(400.13 \mathrm{MHz}, \mathrm{CDCl}_{3}\right) \delta(\mathrm{ppm})$ : 7.29-6.76 (m, 4H), 4.57 (s, 2H, $\left.\mathrm{NH}_{2}\right), 4.40(\mathrm{~s}, 1 \mathrm{H}, \mathrm{CH}), 3.81$ $\left(\mathrm{m}, 3 \mathrm{H}, \mathrm{CH}_{3}\right), 2.47\left(\mathrm{dd}, J=19.6 \mathrm{~Hz}, 2 \mathrm{H}, \mathrm{CH}_{2}\right), 2.26(\mathrm{dd}$, $\left.J=18 \mathrm{~Hz}, 2 \mathrm{H}, \mathrm{CH}_{2}\right), 1.14\left(\mathrm{~s}, 3 \mathrm{H}, \mathrm{CH}_{3}\right), 1.08\left(\mathrm{~s}, 3 \mathrm{H}, \mathrm{CH}_{3}\right)$; ${ }^{13} \mathrm{C}$ NMR $\left(100.22 \mathrm{MHz}, \mathrm{CDCl}_{3}\right) \delta$ (ppm): $27.7\left(\mathrm{CH}_{3}\right), 28.8$
$\left(\mathrm{CH}_{3}\right), 32.2(\mathrm{C}), 35.4\left(\mathrm{CH}_{2}\right), 40.6\left(\mathrm{CH}_{2}\right), 50.6\left(\mathrm{CH}_{3}\right), 55.2$ $(\mathrm{CH}), 63.5(\mathrm{C}), 112.3(\mathrm{CH}), 113.5(\mathrm{CH}), 113.9(\mathrm{C}), 118.6(\mathrm{C})$, $119.9(\mathrm{CH}), 129.6(\mathrm{CH}), 144.8(\mathrm{C}), 157.4(\mathrm{C}), 159.7$ (C), 161.6 (C), $195.8(\mathrm{C})$.

2-Amino-3-cyano-5,6,7,8-tetrahydro-7,7-dimethyl-4-(4chlorophenyl)-5-oxo-4H-benzopyran (4h). m.p. $=213-215^{\circ} \mathrm{C}$; IR $(\mathrm{KBr}) \mathrm{cm}^{-1}$ 3421, $3105\left(\mathrm{NH}_{2}\right), 2185(\mathrm{CN}), 1686(\mathrm{C}=\mathrm{O})$, 1356 (C-O); ${ }^{1} \mathrm{H}$ NMR (400.13 MHz, $\mathrm{CDCl}_{3}$ ) $\delta$ (ppm): 7.25$7.02(\mathrm{~m}, 4 \mathrm{H}), 4.57\left(\mathrm{~s}, 2 \mathrm{H}, \mathrm{NH}_{2}\right), 4.41(\mathrm{~s}, 1 \mathrm{H}, \mathrm{CH}), 2.47$ (s, $2 \mathrm{H}$, $\mathrm{CH}_{2}$ ), $2.24\left(\mathrm{dd}, J=16.4 \mathrm{~Hz}, 2 \mathrm{H}, \mathrm{CH}_{2}\right), 1.14\left(\mathrm{~s}, 3 \mathrm{H}, \mathrm{CH}_{3}\right), 1.05$ (s, $3 \mathrm{H}, \mathrm{CH}_{3}$ ).

\section{Result and Discussion}

In order to optimize the reaction conditions, including solvents and temperature, the reaction was conducted under various conditions and the results are listed in Table 1 . In an optimized reaction condition, benzaldehyde $(1 \mathrm{mmol})$, dimedone $(1 \mathrm{mmol})$, and malononitrile $(1.2 \mathrm{mmol})$ in $\mathrm{H}_{2} \mathrm{O}$ $(10 \mathrm{~mL})$ and $\mathrm{EtOH}(10 \mathrm{~mL})$ were mixed in the presence of 
pentafluoropropionic acid ( $35 \mathrm{~mol} \%$ ) as catalyst for $60-$ $80 \mathrm{~min}$. The reaction proceeds very cleanly at room temperature and was free of side products. After completion of the reaction (monitored by TLC), a simple workup affords the products in high yields (Scheme 1). Among the solvents tested, the reaction in $\mathrm{H}_{2} \mathrm{O}$, EtOH, $\mathrm{CHCl}_{3}$, and $\mathrm{CH}_{3} \mathrm{CN}$ using $35 \mathrm{~mol} \%$ of the catalyst gave a moderate yield of the desired product at room temperature. However in the mixture of EtOH and $\mathrm{H}_{2} \mathrm{O}$ relatively high yield of the product is obtained at room temperature after $80 \mathrm{~min}$. Without catalyst, in refluxing $\mathrm{EtOH}, \mathrm{H}_{2} \mathrm{O}, \mathrm{CHCl}_{3}, \mathrm{CH}_{3} \mathrm{CN}$, and mixture of EtOH- $\mathrm{H}_{2} \mathrm{O}$ or at room temperature in this solvents the reaction times are prolonged and the yields are poor. In the solvent-free conditions, even in the presence of $40 \mathrm{~mol} \%$ of the catalyst at room temperature, the yields are moderate. The results are summarized in Table 1. For comparison, we also investigated the efficiency of trifluoroacetic acid (TFAA) as catalyst in this model reaction. As shown in Table 1, it can be seen that PFPA proved to be a better catalyst than TFAA in terms of reaction time and yield.

We also evaluated the amount of pentafluoropropionic acid required for this transformation. It was found that the yield of product was affected by the catalyst amount. Increasing the amount of the catalyst up to $35 \mathrm{~mol} \%$ in the mixture of $\mathrm{EtOH}$ and $\mathrm{H}_{2} \mathrm{O}$ at room temperature increased the yield of the product. Further increase in the catalyst amount did not increase the yield noticeably. In order to show generality and scope of this new protocol, we used various substituted aromatic aldehydes and the results obtained are summarized in Table 2.

In all cases, aromatic aldehydes with substituents carrying either electron-donating or electron-withdrawing groups reacted successfully and gave the expected products in high yields and short reaction times. The type of aldehyde had no significant effect on the reaction. The efficiency of pentafluoropropionic acid as a catalyst for the synthesis of the 2-amino-3-cyano-5,6,7,8-tetrahydro-7, 7-dimethyl5-oxo-4-phenyl-4H-benzopyran (4a), was compared with that of other catalysts reported in the literature. Some of the results are summarized in Table 3. It is clear from this table that pentafluoropropionic acid is an efficient and environmentally benign catalyst which could be useful in the synthesis of a series of tetrahydrobenzo[b]pyran derivatives.

\section{Conclusion}

In conclusion, a mild and efficient method is proposed for the one-pot three-component reactions of aromatic aldehydes, dimedone, and malononitrile using pentafluoropropionic acid catalyst for synthesis of tetrahydrobenzo $[b]$ pyran derivatives. Some attractive features of this protocol are high yields, easy workup, and the simplicity of the procedure.

\section{Conflict of Interests}

The authors declare that there is no conflict of interests regarding the publication of this paper.

\section{Acknowledgment}

This research has been supported by the Islamic Azad University, Tonekabon Branch.

\section{References}

[1] L. L. Andreani and E. Lapi, "On some new esters of coumarin3-carboxylic acid wit balsamic and bronchodilator action," Bollettino Chimico Farmaceutico, vol. 99, pp. 583-586, 1960.

[2] L. Bonsignore, G. Loy, D. Secci, and A. Calignano, "Synthesis and pharmacological activity of 2-oxo- $(2 H)$ 1-benzopyran-3carboxamide derivatives," European Journal of Medicinal Chemistry, vol. 28, no. 6, pp. 517-520, 1993.

[3] A. Saini, S. Kumar, and J. S. Sandhu, "A new LiBr-catalyzed, facile and efficient method for the synthesis of 14-alkyl or aryl$14 \mathrm{H}$-dibenzo[a,j]xanthenes and tetrahydrobenzo[b]pyrans under solvent-free conventional and microwave heating," Synlett, vol. 12, pp. 1928-1932, 2006.

[4] K. Singh, J. Singh, and H. Singh, "A synthetic entry into fused pyran derivatives through carbon transfer reactions of 1,3-oxazinanes and oxazolidines with carbon nucleophiles," Tetrahedron, vol. 52, no. 45, pp. 14273-14280, 1996.

[5] E. C. Witte, P. Neubert, and A. Roesch, "7-(piperazinyl propoxy)-2H-1-benzopyran-2-ones. Ger. Offen DE," Chemical Abstracts, vol. 104, Article ID 224915f, 1986.

[6] X. S. Wang, D. Q. Shi, S. T. Tu, and C. S. Yao, "A convenient synthesis of 5-Oxo-5,6,7,8-tetrahydro-4 $\mathrm{H}$-benzo- $[b]$ pyran derivatives catalyzed by KF-alumina," Synthetic Communications, vol. 33, no. 1, pp. 119-126, 2003.

[7] S. Hatakeyama, N. Ochi, H. Numata, and S. Takano, "A new route to substituted 3-methoxycarbonyldihydropyrans; enantioselective synthesis of (-)-methyl elenolate," Journal of the Chemical Society, Chemical Communications, no. 17, pp. 12021204, 1988.

[8] G. R. Green, J. M. Evans, A. K. Vong, A. R. Katritzky, C. W. Rees, and E. F. Scriven, "Comprehensive heterocyclic chemistry II," in Pyrans and Their Benzo Derivatives Synthesis, vol. 5, p. 469, Pergamon Press, Oxford, UK, 1995.

[9] D. Armesto, W. M. Horspool, N. Martin, A. Ramos, and C. Seoane, "Synthesis of cyclobutenes by the novel photochemical ring contraction of 4-substituted 2-amino-3,5-dicyano-6phenyl-4H-pyrans," Journal of Organic Chemistry, vol. 54, no. 13, pp. 3069-3072, 1989.

[10] S. S. Katkar, M. K. Lande, B. R. Arbad, and S. T. Gaikwad, "A recyclable and highly effective $\mathrm{ZnO}$-beta zeolite as a catalyst for one-pot three-component synthesis of tetrahydrobenzo[b]pyrans," Chinese Journal of Chemistry, vol. 29, no. 1, pp. 199-202, 2011.

[11] I. Devi and P. J. Bhuyan, "Sodium bromide catalysed one-pot synthesis of tetrahydrobenzo[b]pyrans via a three-component cyclocondensation under microwave irradiation and solvent free conditions," Tetrahedron Letters, vol. 45, no. 47, pp. 8625$8627,2004$.

[12] R. Hekmatshoar, S. Majedi, and K. Bakhtiari, "Sodium selenate catalyzed simple and efficient synthesis of tetrahydro benzo[b]pyran derivatives," Catalysis Communications, vol. 9, no. 2, pp. 307-310, 2008.

[13] H. A. Oskooie, M. M. Heravi, N. Karimi, and M. Ebrahimzadeh, "Caro's acid-silica gel: an efficient and versatile catalyst for the one-pot synthesis of tetrahydrobenzo[b]pyran derivatives," Synthetic Communications, vol. 41, no. 3, pp. 436-440, 2011. 
[14] J. Zheng and Y. Q. Li, "One-pot synthesis of tetrahydrobenzo $[b]$ pyran and dihydropyrano $[c]$ chromene derivatives in aqueous media by using trisodium citrate as a green catalyst," Scholars Research Library, vol. 3, no. 2, pp. 381-388, 2011.

[15] A. Davoodnia, S. Allameh, S. Fazli, and N. Tavakoli-Hoseini, "One-pot synthesis of 2-amino-3-cyano-4-arylsubstituted tetrahydrobenzo $[b]$ pyrans catalysed by silica gel-supported polyphosphoric acid (PPA-SiO2) as an efficient and reusable catalyst," Chemical Papers, vol. 65, no. 5, pp. 714-720, 2011.

[16] J. T. Li, W. Z. Xu, L. C. Yang, and T. S. Li, "One-pot synthesis of 2-amino-4-aryl-3-carbalkoxy-7,7-dimethyl-5,6,7,8tetrahydrobenzo[b]pyran derivatives catalyzed by $\mathrm{KF} / \mathrm{Basic}$ $\mathrm{Al} 2 \mathrm{O} 3$ under ultrasound irradiation," Synthetic Communications, vol. 34, no. 24, pp. 4565-4571, 2004.

[17] D. Shi, J. Mou, Q. Zhuang, and X. Wang J, "One-pot synthesis of 2-amino-4-aryl-5-oxo-5,6,7,8-tetrahydro-4H-1-benzopyran3 -carbonitriles in aqueous media," Journal of Chemical Research, vol. 2004, no. 12, pp. 821-823, 2004.

[18] B. C. Ranu, S. Banetjee, and S. Roy, "A task specific basic ionic liquid, [bmIm] OH-promoted efficient, green and onepot synthesis of tetrahydro-benzo[ $b]$ pyran derivatives," Indian Journal of Chemistry B, vol. 47, no. 7, pp. 1108-1112, 2008.

[19] K. S. Niralwad, K. F. Shelke, S. S. Sadaphal, B. B. Shingate, and M. S. Shingare, "An efficient and green synthesis of tetrahydrobenzo[b]pyran derivatives catalysed by sodium hypochlorite by grinding," Bulletin of the Catalysis Society of India, vol. 8 , pp. 188-192, 2009.

[20] J. Azizian, A. Shameli, S. Balalaie et al., "The one-pot synthesis of pyrano[2,3-d]pyrimidinone derivatives with 1,4diazabicyclo[2.2.2] octane in aqueous media," Oriental Journal of Chemistry, vol. 28, no. 1, pp. 327-332, 2012.

[21] A. M. Shestopalov, Y. M. Emelianova, and V. N. Nesterov, "One-step synthesis of substituted 2-amino-5,6,7,8-tetrahydro$4 H$-benzo[b]pyrans. Molecular and crystal structure of 2-amino-3-(2-methoxyethoxycarbonyl)-4-(2-nitrophenyl)-5oxo-5,6,7,8-tetrahydro- $4 H$-benzo[b]pyran," Russian Chemical Bulletin International Edition, vol. 52, no. 5, pp. 1164-1171, 2003.

[22] S. Rathod, B. Arbad, and M. Lande, "Preparation, characterization, and catalytic application of a nanosized CelMgxZr1$x \mathrm{O} 2$ solid heterogeneous catalyst for the synthesis of tetrahydrobenzo[b]pyran derivatives," Chinese Journal of Catalysis, vol. 31, no. 6, pp. 631-636, 2010.

[23] R. L. Magar, P. B. Thorat, V. B. Jadhav, S. U. Takale, S. A. Patil, and R. P. Pawar, "Silica gel supported polyamine: a versatile catalyst for one pot synthesis of 2-amino- $4 H$-chromene derivatives," Journal of Molecular Catalysis A: Chemical, vol.374-375, pp.118$124,2013$.

[24] N. Azizi, S. Dezfooli, M. Khajeh, and M. Mahmoudi Hashemi, "Efficient deep eutectic solvents catalyzed synthesis of pyran and benzopyran derivatives," Journal of Molecular Liquids, vol. 186, pp. 76-80, 2013.

[25] S. Khaksar, A. Rouhollahpour, and S. Mohammadzadeh Talesh, "A facile and efficient synthesis of 2-amino-3-cyano$4 H$-chromenes and tetrahydrobenzo[b]pyrans using 2,2,2trifluoroethanol as a metal-free and reusable medium," Journal of Fluorine Chemistry, vol. 141, pp. 11-15, 2012.

[26] S. Balalaie, M. Sheikh-Ahmadi, and M. Bararjanian, "Tetramethyl ammonium hydroxide: an efficient and versatile catalyst for the one-pot synthesis of tetrahydrobenzo[b]pyran derivatives in aqueous media," Catalysis Communications, vol. 8, no. 11, pp. 1724-1728, 2007.
[27] K. A. Undale, Y. Park, K. Park, D. H. Dagade, and D. M. Pore, "A revisit to the hantzsch reaction: unexpected formation of tetrahydro-benzo[b]pyrans beyond polyhydroquinolines," Synlett, no. 6, pp. 791-796, 2011.

[28] S. Gurumurthi, V. Sundari, and R. Valliappan, "An efficient and convenient approach to synthesis of tetrahydrobenzo $[b]$ pyran derivatives using tetrabutylammonium bromide as catalyst," $E$ Journal of Chemistry, vol. 6, supplement 1, pp. S466-S472, 2009.

[29] N. Montazeri, S. Khaksar, A. Nazari, S. S. Alavi, S. M. Vahdat, and M. Tajbakhsh, "Pentafluorophenylammonium triflate (PFPAT): an efficient, metal-free and reusable catalyst for the von Pechmann reaction," Journal of Fluorine Chemistry, vol. 132, no. 7, pp. 450-452, 2011.

[30] N. Montazeri, K. Pourshamsian, S. Yosefiyan, and S. Momeni, "Pentafluorophenylammonium triflate- $\mathrm{CuCl}_{2}$ : a mild, efficient and reusable heterogeneous catalyst system for facile synthesis of 4(3H)-quinazolinones under solvent-free conditions," Journal of Chemical Sciences, vol. 124, no. 4, pp. 883-887, 2012.

[31] N. Montazeri and S. Mahjoob, "Highly efficient and easy synthesis of 2,4,6-triarylpyridines catalyzed by pentafluorophenylammonium triflate (PFPAT) as a new recyclable solid acid catalyst in solvent-free conditions," Chinese Chemical Letters, vol. 23, no. 4, pp. 419-422, 2012.

[32] N. Montazeri and K. Rad-Moghadam, "An expeditious and one-pot synthesis of unsymmetrical 2,5-disubstituted-1,3,4oxadiazoles under microwave irradiation and solvent-free conditions," Chinese Chemical Letters, vol. 19, no. 10, pp. 1143-1146, 2008. 

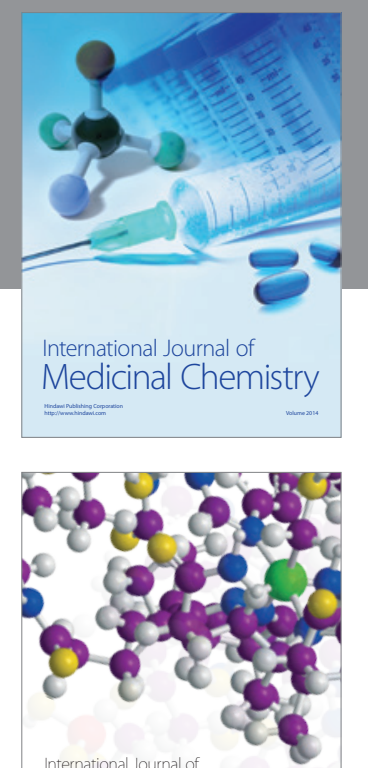

\section{Carbohydrate} Chemistry

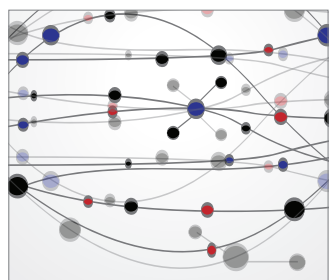

The Scientific World Journal
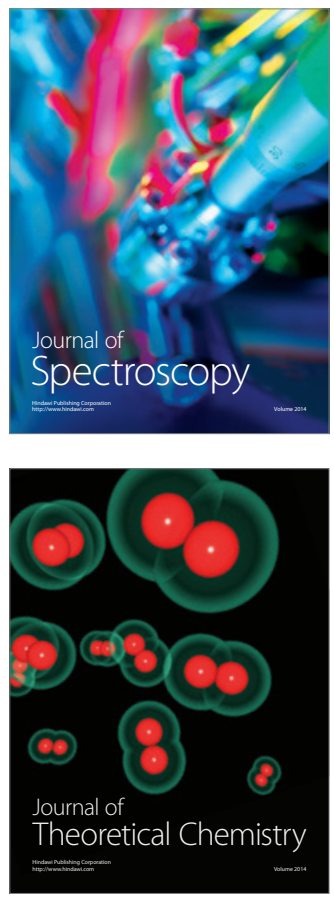
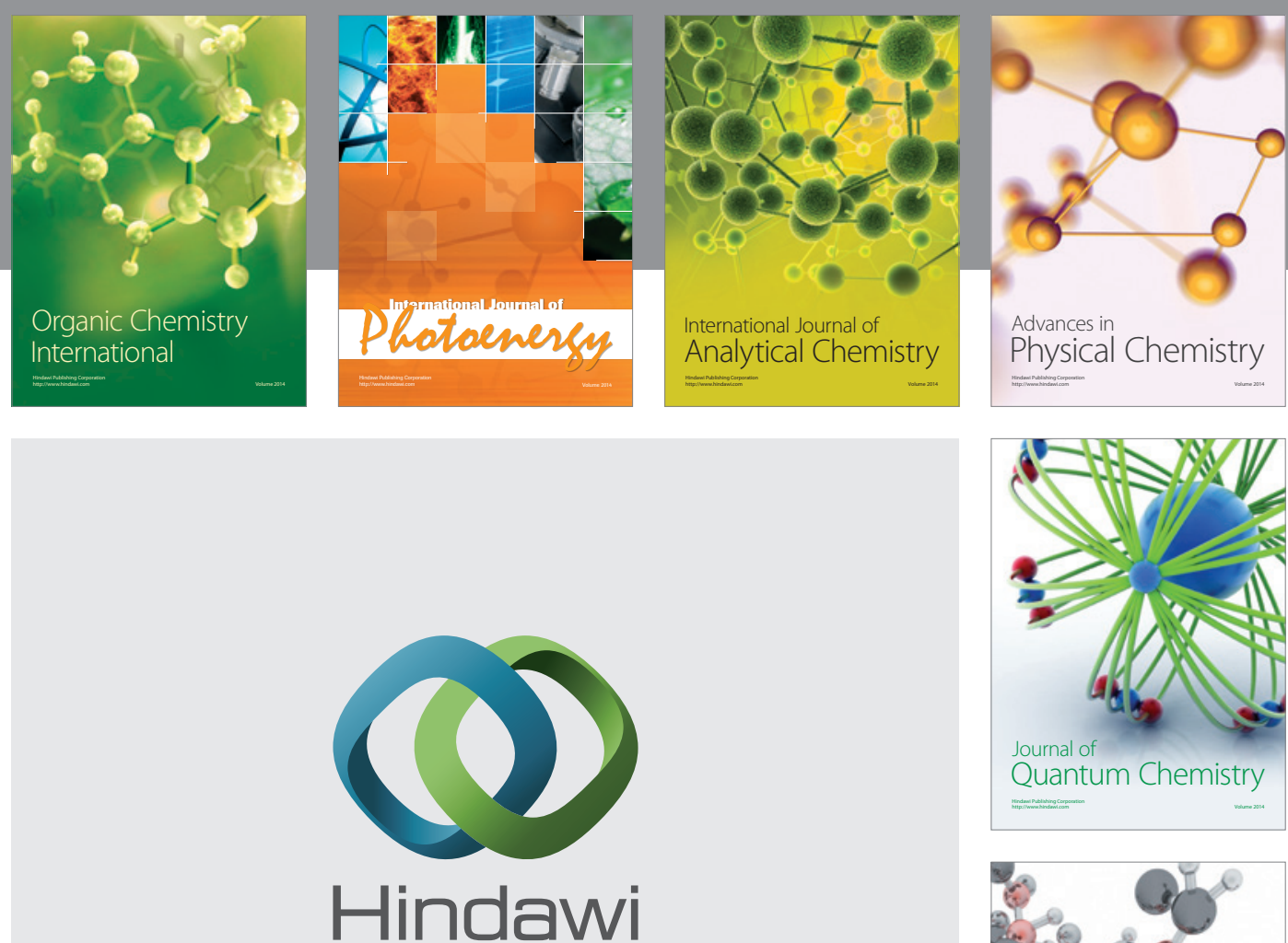

Submit your manuscripts at

http://www.hindawi.com

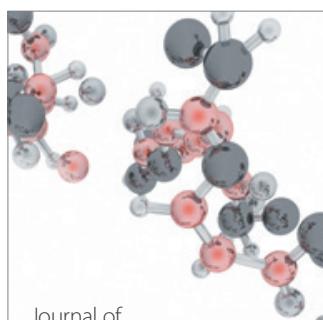

Analytical Methods

in Chemistry

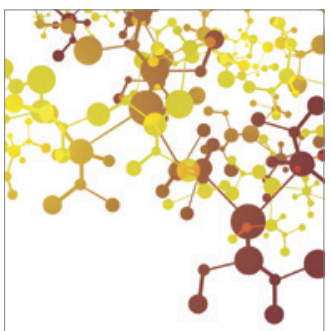

Journal of

Applied Chemistry

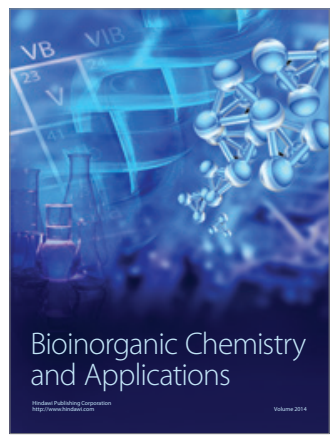

Inorganic Chemistry
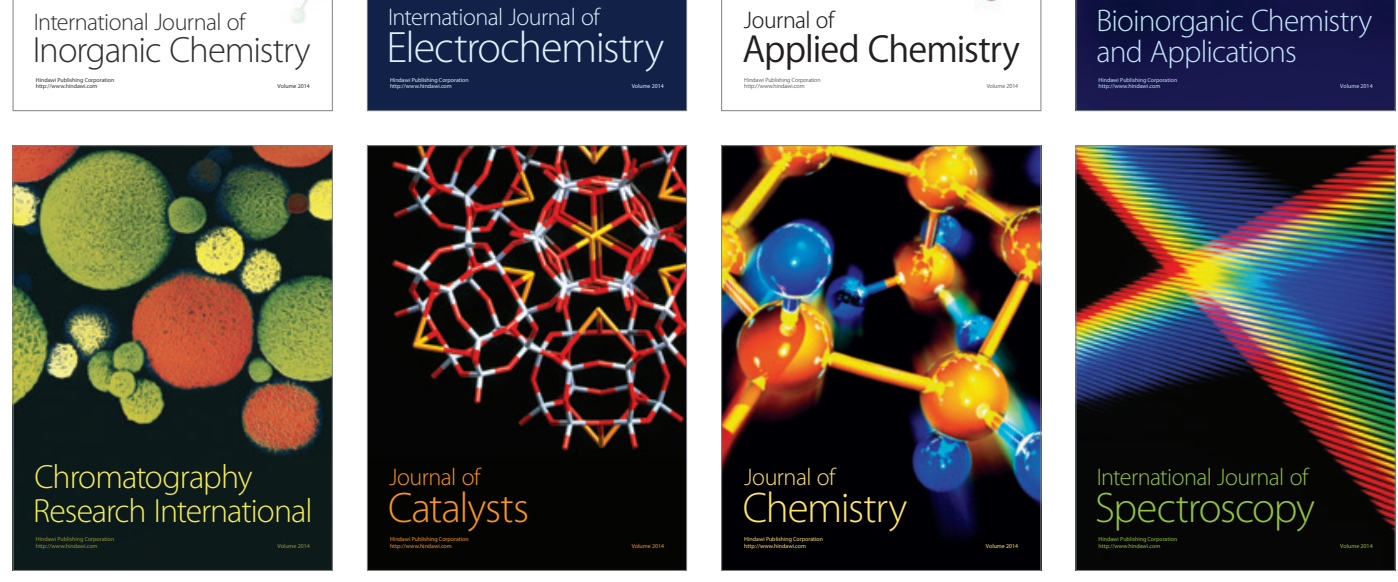